\title{
تقويم الكتاب التعليمي"العربية للناشئين" لتعليم اللغة العربية لغير الناطقين بها
}

\author{
عبد العزيز صديق \\ قسم التربية الإسلامية بتخصص تعليم اللغة العربية كلية الدراسات العليا \\ جامعة السلطان الشريف قاسم الإسلامية الحكومية رياو. \\ a.azizshidiq@gmail.com
}

تجريد: لقد انتشرت الكتب التعليمية يستخدمها بعض المدارس والمعاهد في أنحاء أندونيسيا لتدريس اللغة

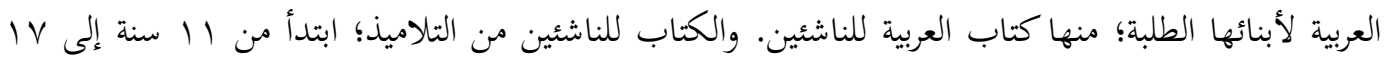

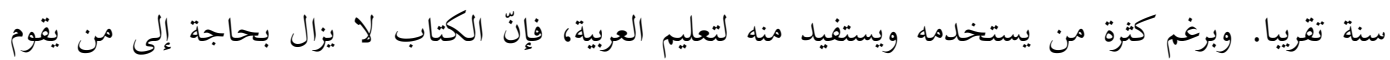
بتقويمه؛ اعتمادا على المعايير والأسس التي ذكرها المتخصصون في إعداد الكتاب التعليمي للغة العربية. والأهداف من عملية هذا البحث هي لمعرفة محتويات الكتاب التعليمي "العربية للناشئين" ومطابقته لتعليم اللغة العربية لغير الناطقين بها.

ويعتبر هذا البحث من ضمن البحث المكتب، والطريقة لجمع البيانات هي منهج التوثيق. وتحليل بياناتها يستخدم الباحث المدخل الاستقرائي العامي. والنتائج هي؛ أولا: ما يتعلق بمحتويات كتاب التعليمي "العربية للناشئين" وهي أسس إعداد الكتاب؛ يتكون من الأسس الثقافية الاجتماعية، والأسس السيكولوجية، والأسس اللغوية والتربية، ومحتوى الكتاب؛ يشتئه على المادة اللغوية وهي : المفردات، التراكيب، ونوع اللغة المعلمةو هي اللغة العربية الفصحى، والثقافية وهي الثقافة العربية والإسلامية، المهارات اللغوية؛ وهي الاستماع والكلام والقراءة والكتابة، وطريقة التدريس؛ ولهي؛ فيستخدم الكتاب الطريقة السمعية الشفوية في تعليم اللغة العربية، والتدريبات؛ فالكتاب يحتوي على ثلاثة أنواع التدريبات وهي: التدريبات الآلية/تدريبات الأنماط، تدريبات المعنى، التدريبات الاتصالية، والمواد المصاحبة، يتكون من كتب التدريبات والتمرينات، والصور، ومرشد المعلم أو كتاب المعلم، وإخراج الكتاب؛ وهو من ونسي

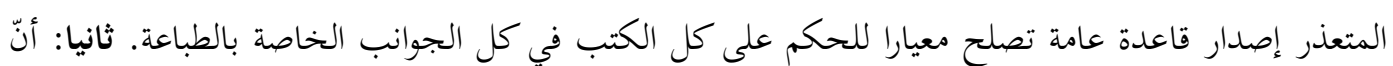
كتاب العربية للناشئين مطابق لتعليم اللغة العربية لغير الناطقين بها عموما. كلمات البحث : التقويم، الكتاب التعليمي، العربية للناشئين، المعيار. 


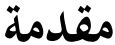

إنّ الكتاب التعليمي أو ما يسمى بالكتاب المدرسي له دور كبير في نجاح عملية

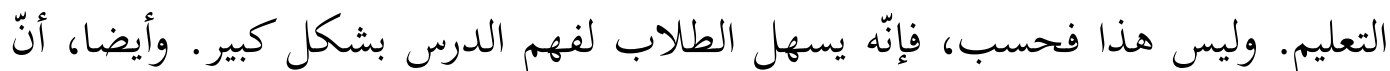
الكتاب التعليمي من الوسائل التعليمية التي يستحب لئيل استخدامه لإيصال العلوم

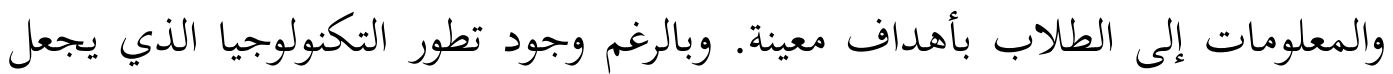
عملية التعليم والتعلم أسهل عملية، لكن استخدام الكتاب التعليمي قد ثبت نفعه لدى

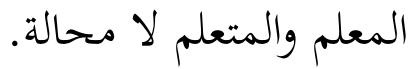

وفي تعليم اللغة العربية، فإنّ هناك مناهج مختلفة فيما بين تعليم من يتكلم بها وتعليم الناطقين بغيرها. فالكتاب التعليمي لمن يتكلم بها مختلف بمن يتكلم بغيرها. فشعب أندونيسيا مثلا، هم الذين يتكلمون بغير العربية فلهم مناهج خاصة بهم. ولقد انتشرت الكتب التعليمية يستخدمها بعض المدارس والمعاهد في أنحاء

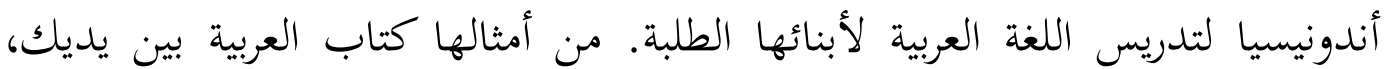
وكتاب العربية للناشئين، وكتاب دروس اللغة العربية لمعهد غنطور، وكتاب دروس اللغة العربية للجامعة الإسلامية المدينة، وكتاب سلسلة تعليم اللغة العربية للناطقين بغيرها وغيرها من أمثلة الكتب التعليمية. تلك الكتب للطلاب الناطقين بغيرها.

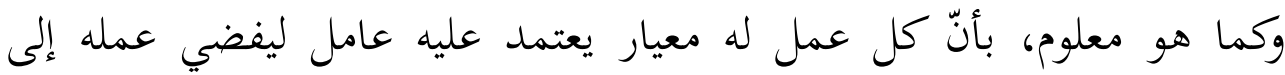
هدف معين، فتأليف الكتب التعليمية -خاصة في تعليم اللغة العربية-، كذلك له معيار ومسلك يحثّ على المؤليفين كي يسلكوا على ذلك المسلك ويتمسكون عليه ليوصلهم إلى نجاح عمالية التعليم.

ومن ثمّ ألف المتخصصون كتبا تتكلم عن إعداد تأليف الكتب التعليمية للغة العربية، حيث ذكروا فيها المعايير والأسس لإعدادها، دليلا على من له رغبة في تأليف كتب تعليمية للغة العربية، ورجاء على جميع المؤلفين كي يهتموا بها أولا قبل إصدارها. وبغض النظر عن ذلك، فإنّ عدد الكتب لتعليم اللغة العربية قد انتشرت وكثر إصدارها في مجتمعنا. ولا يكون جميع الكتب التعليمية مطابقة بالمعايير التي ذكرها 
المتخصصون. فيترتب على ذلك ظهور بعض تساؤلات تتعلق بكتاب استخدمه مدرس

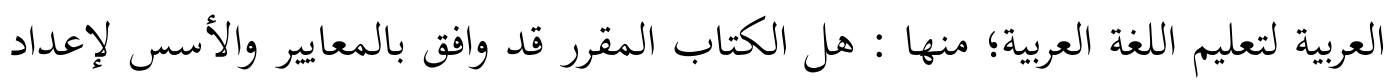

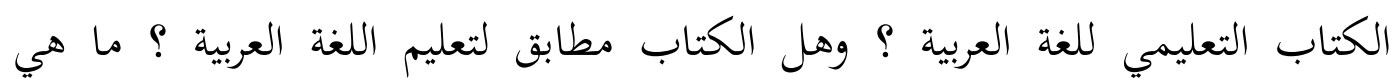
المميزات والعيوب في ذاك الكتاب ؟ وهل الكتاب بحاجة إلى التقويم؟؟ وهلمّ جرا. فلذلك معفرفة أداة تقويم كتب تعليم العربية لها أهداف يبين أحد المتخصصين كما يلي :

1. التعريف بالعناصر التي ينبغي أن تشتغل مؤلفي كتب تعليم العربية وبيان الوزن

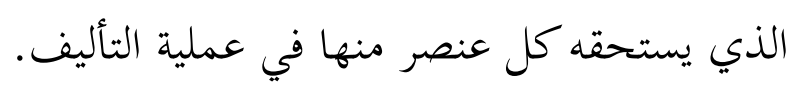

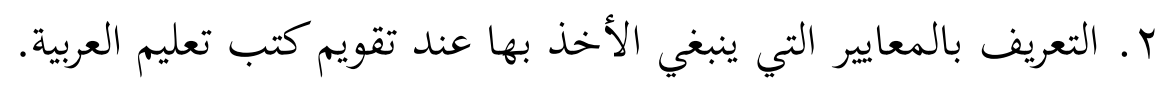
r. وضع المعايير السابقة في شكل أداة موضوعية لتقويم كتب تعليم العربية.

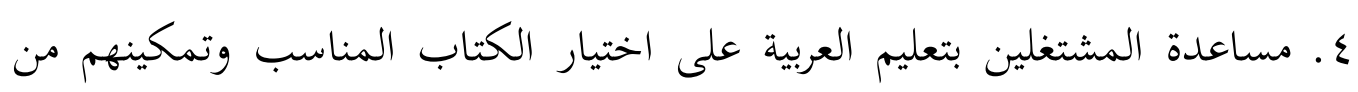
الحكم على ما بين أيديهم من كتب. هـ فتح الباب أمام الدراسات المستقبلية الخاصة بتقويم كتب تعليم العربية سواء منها

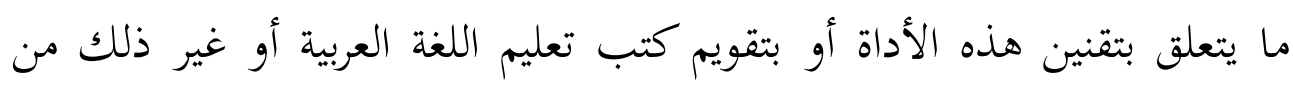

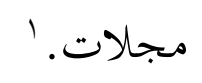
فمن هذه الظواهر، رأى الباحث أهمية القيام بالبحث العلمي على كتاب العربية

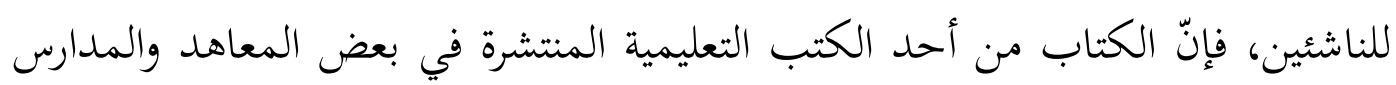
لتعلم اللغة العربية في أندونيسيا. وكان الباحث يعلّم به الطلاب اللغة العربية في معهد

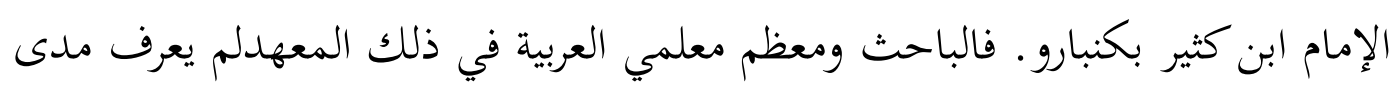
مناسبة هذا الكتاب بالمعايير التي ذكرها المتخصصون في كتبهم.

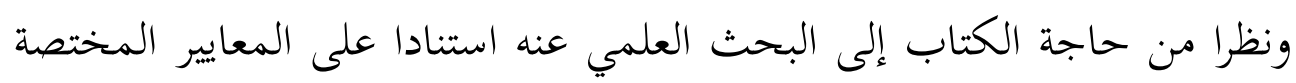

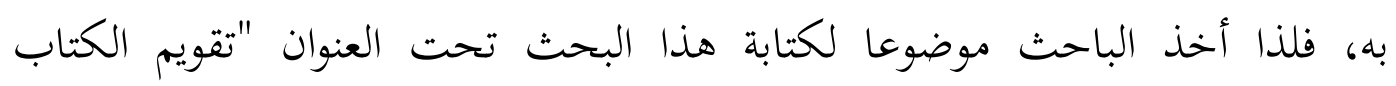
'رشدي أحمد طعيمة، دليل عمل في إعداد المواد الثعليمية لبوامج تعليم العربية، (مكة: جامعة أم القرى، 
التعليمي العربية للناشئين لتعليم اللغة العربية لغير الناطقين بها" رجاء لمعرفة محتويات الكتاب ومطابقته لتعليم اللغة العربية.

\section{الإيطار النظري ونتائج البحث}

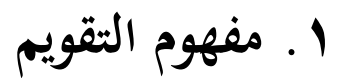

التقويم هو مجموع الإجراءات التي يتم بواسطتها جمع بيانات خاصة بفرد أو

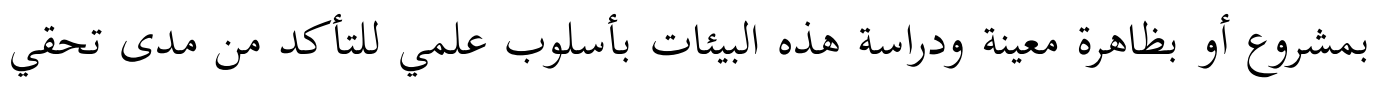

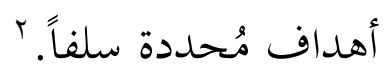

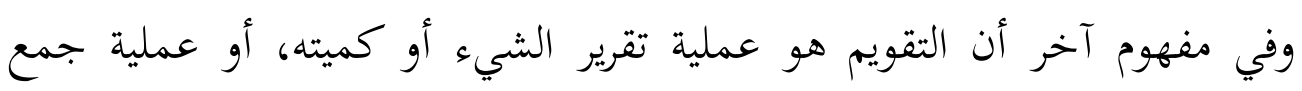
معلومات عن ظاهرة ما، وتصنيف هذه المعلومات أو البيانات وتحليلها وتفسيرها سواء اء كمية أو كفية.

وأيضا من المفهومات لكلمة التقويم أنّه الفعل الذي بواسطة نصدر حكما على

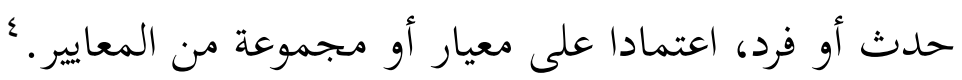

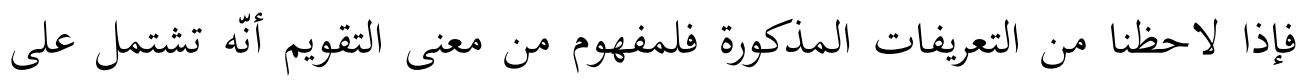

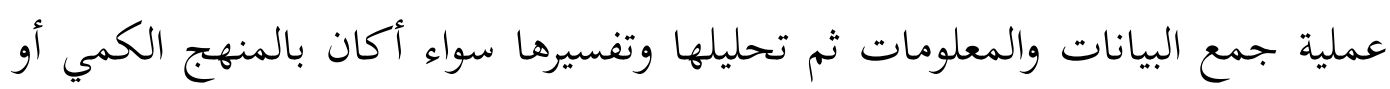
الكيفي؛ لإصدار حكم على شيء اعتمادا على المعايير المعينة.

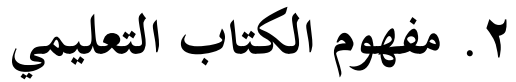

الكتاب التعليمي أو ما يسمى بالكتاب المدرسي في الدراسة الحالية يعني ذلك بك

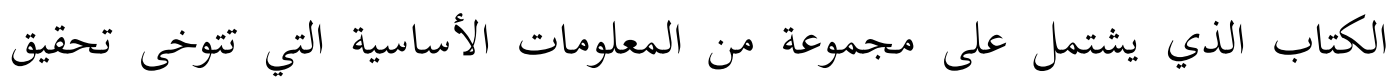

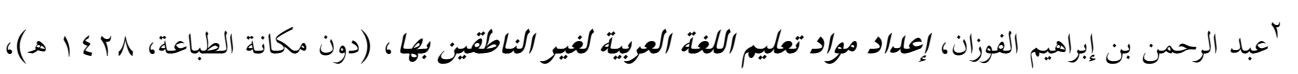
ص. 19 'حسن شحاتة وزينب النجار، معجم المصطلحات التربوية زالنفسية، (القاهرة: دار المصرية اللبنانية، ب . بم)، ط.

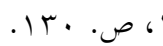
"محمد الدريج والأصدقاء، معجم مصطلحات المناهج وطرق الثدريس، (الرباط :مكتب تنسيق التعريب في الوطن 
أهداف تربوية محددة سلفا. (معرفية Cognitive أو وجدانية Affective أو نفسحركية -Psychomotoric

وفي مفهوم آخر، أنّ الكتاب المدرسي هو الكتاب الأساسي للطالب وما يصحبه من مواد تعليمية مساعدة، والتي تؤلف من قبل المتخصصين في التربية واللغة،

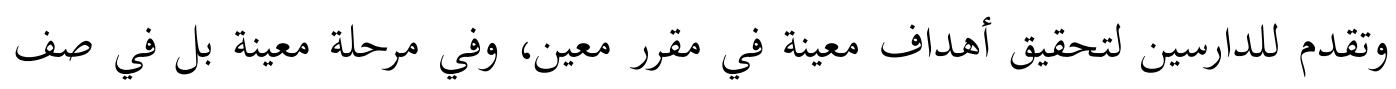
دراسي معين وفي وزمن محدد.

إذن الكتاب التعليمي هو الكتاب الأساسي للطالب وما يصحبه من مواد تعليمية مساعدة، والتي تؤلف من قبل المتخصصين في التربية واللغة، وتقدم للدارسين لتحقيق

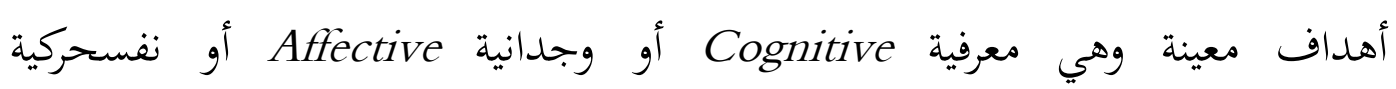
Psychomotoric

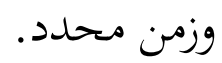

\section{ب. تعريف كتاب العربية للناشئين أ) تعريف مؤلف كتاب العربية للناشئين}

كتاب العربية للناشئين ألفه مجموعة من المؤلفين وهم محمود إسماعيل صيني وناصف مصطفى عبد العزيز ومختار الطاهر حسين. وهم الثلاثة الذين ألّفوا سلسلة أحبّ العربية. ب) اللمحة عن كتاب العربية للناشئين

"محمود كامل الناقة ورشدي أحمد طعيمة، الكتاب الأساسي لثعليم اللغة العببية للناطقين بلغات أخري، (مكة:

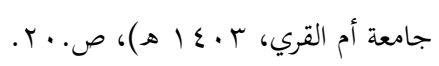
" ناصر عبد الله الغالي وعبد المجيد عبد المبه اله، أسس إعداد الكتب التعليمية لغير الناطقين بالعربية، (دون مكان الطباعة، دار الاعتصام، دون السنة)، ص. 9. 
جاء تأليف كتاب سلسلة العربية للناشئين بالتعاون بين وزارة المعارف ومعهد تعليم اللغة العربية بجامعة الرياض (جامعة الملك سعود حاليا). وهذا الكتاب للناشئين

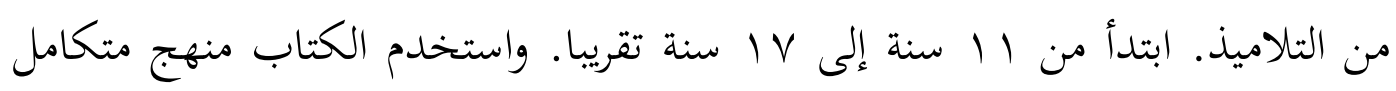
في تعليم اللغة العربية لغير الناطقين بها. تتكون السلسلة من ستة كتب للتلميذ تصححها ستة كتب للعلم. مع تسجيلات صوتية للنصوص الأساسية ولمعظم تدريبات الكتاب بالإضافة إلى المعينات البصرية. تستخدم السلسلة اللغة العربية الفصحى وتقدم للدارس أنماطا من الثقافة العربية الإسلامية وألوانا من الثقافة العامة. تهتدي السلسلة بأفضل الطرائق والأسالب المستخدمة في تعليم اللغات الأجنبية والتي ثبت جدواها من الناحية العملية مع مراعات طبيعة اللغة العربية بخصائصها المتفردة.

تقوم السلسلة على مبدأ التكامل بين المهارات والعناصر اللغوية المختلفة حيث يمارس الدارس مهارات اللغة من استماع وكلام وقراءة وكتابة في اتساق وتوازن ويتدرب على عناصرها من أصوات ومفردات ونحو بتحكم دقيق في وحدات الكتاب التعليمية. وينطلق العمل في السلسلة من وحدة التعليمية باعتبارها مركز النشاط والفعالية الذي تتجمع فيه كل أنواع الأنشطة اللغوية. يتضمن كتاب المعلم الطرائق التي يتبعها المعلم عند تدريس محتويات كتاب لتهبل

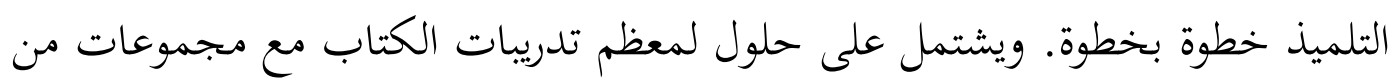
الأنشطات الإضافية.

\section{ع .عناصر تقويم الكتاب التعليمي}

العناصر الرئيسية لتقويم الكتاب التعليمي تشتمل على عدة الأمور، وهي : 
أ) أسس إعداد الكتاب: ويقصد بذلك تعرف المراحل التي سبقت إخراج الكتاب في شكله النهائي بما في ذلك الدراسات والبحوث التي يرجع إنداد إليها المؤلفون وكذلك المنطلقات التي استندوا إليها.

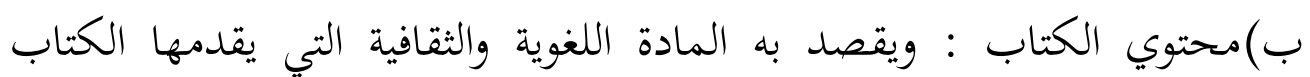

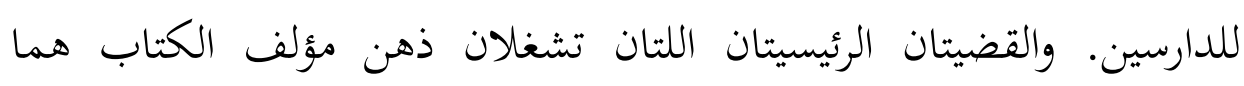
اختيار المحتوى وتنظيمه. من هنا فقد تنوعت الأسئلة التي تندرج تحت هذا المجال لتشتمل مختلف عناصر المحتوى (المفردات والتراكيب وتعليم القواعد ونوع اللغة المعلمة والمضمون الثقافي) سواء فيما يخصّ اختيار المحتوى أو تنظيمه.

ج) المهارات اللغوية : ويقصد بها المهارات العامة والتفصيلية التي يتحوى الكتاب اكسابها للدارسين، استماعا وكلاما وقراءة وكتابة.

د) طريقة التدريس : ويقصد بذلك تعرف طريقة تعليم اللغات الأجنبية التي يتبناها المؤلفون والتي تنعكس بدورها على اختيار الكتاب وتنظيمه.

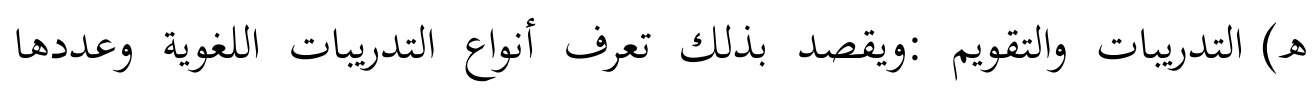
ومدى قدرتها على تثبيت المهارات اللغوية التي يسعى لاكسابها للدارسين وكذلك تعرف أسلوب التقويم الذي يشيع في الكتاب والذي يمكن من خلاتله تعرف مدى تحقيق أهداف الكتاب. و) المواد المصاحبة : ويقصد بها مختلف الأدوات التي تصحب اهب الكتاب وتساعد على تحقيق أهدافه بكفاءة مثل دليل المعلم وشرائط التسجيل وكراسة التدريبات، وغير ذلك من أدوات.

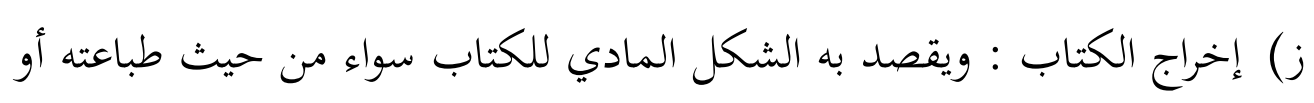
تنظيمه بشكل عام أو الوسائل التعليمية التي يوظفها. 
ح) الانطباق العام : ويقصد بذلك تعرف مدى مناسبة الكتاب للبرنامج الذي يختار له وكذلك إحساس المعلم لاستخدامه.

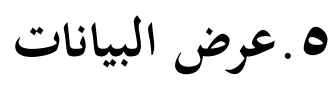

كتاب العربية للناشئين هو من أحد الكتب التعليمية للغة العربية التي طبعت من

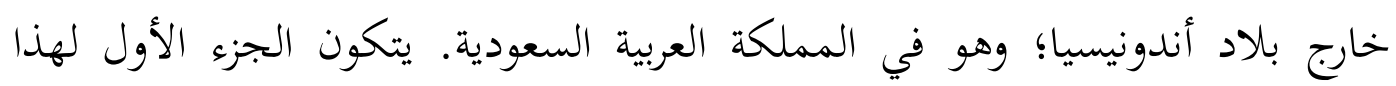

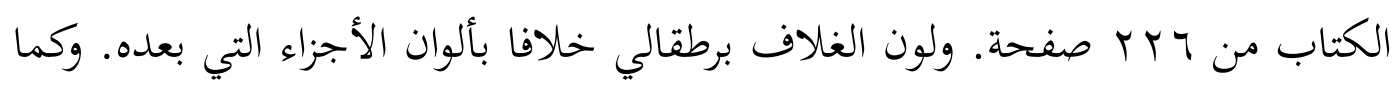

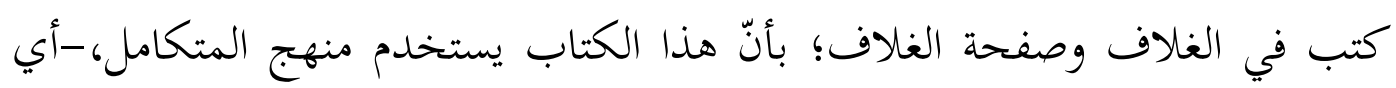

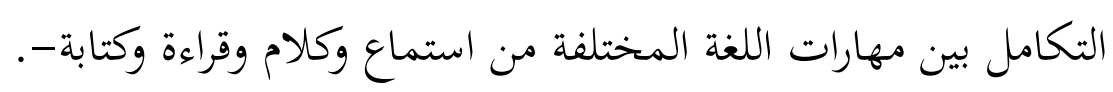

وفي الصفحات بعد صفحة الغلاف، يشتمل الكتاب على المحتويات والتوجيه

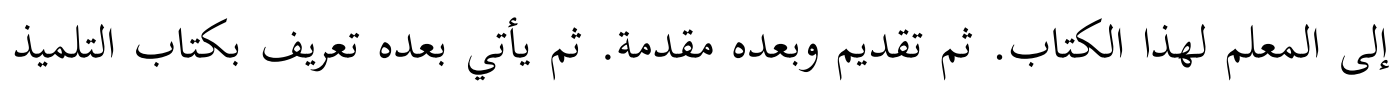

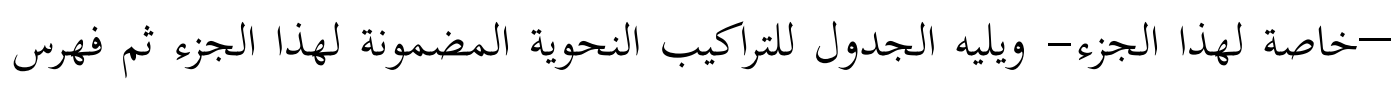

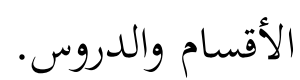

وكما هو المذكور في تعريف بكتاب التلميذ؛ بأنّ الكتاب الأول من سلسلة

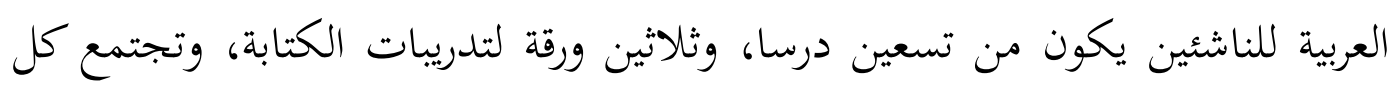

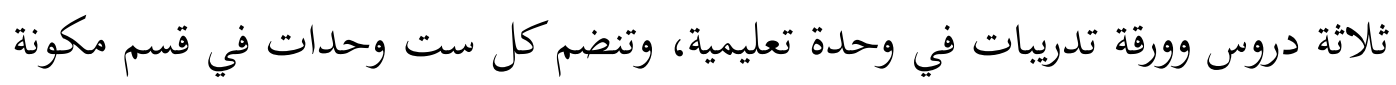
خمسة أقسام مصنفة حسب الموضوعات الثقافية.

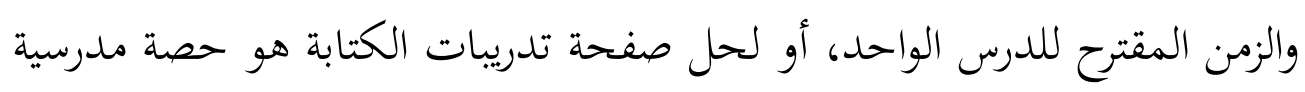

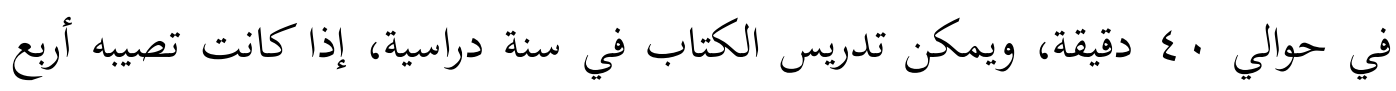
حصص أسبوعيا. على مدى ثلاثين أسبوعا.

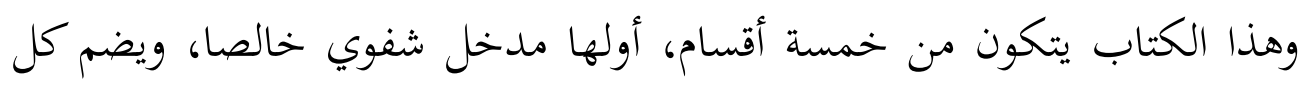
قسم ست وحدات تعليمية، تختص وحدة السادسة في كل قسم لمراجعة ما درس في الوحدات الخمس السابقة لها.

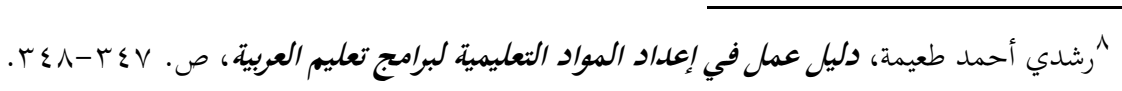


في الأقسام الأربعة الأولى، تتكون كل وحدة من ثلاثة دروس وصفحة تدريبات

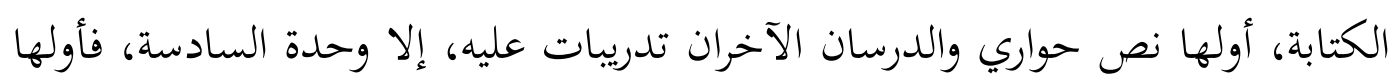
نص قرائي لتثبيت ما درس في الحوارات الخسمة، ثم درسان للتدريبات والمراجعة. أما القسم الخامس والأخير من الكتاب فيقدم عشرة نصوص حوارية وتدريباتها في الوحدات من الأولى حتى الخامسة، معدل حوارين في كل وحدة، وثلاثة نصوص وند قرائية وتدريباتها في الوحدة السادسة.

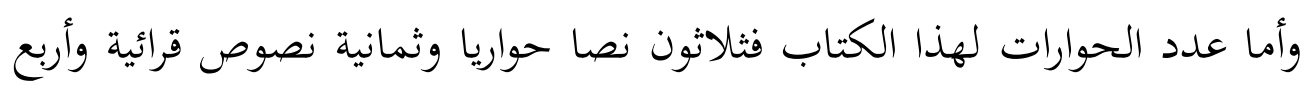
مائة وخمسة وأربعون (0 ع § ) مفردة والتعبيرات الحية. ثم في نهاية كل وحدة تعليمية صفحة التدريبات الكتابة لتقويم التلميذ فيما درسه في الدروس الثلاثة للوحدة وبصورة متدرجة. وكما ذكر في المقدم، أنّ هذا الجزء يشتمل على خمسة أنهاء أقسام، فتفصيله كما : () القسم الأول يستخدم في هذا القسم مدخل شفوي خالص. وهو يحتوي على

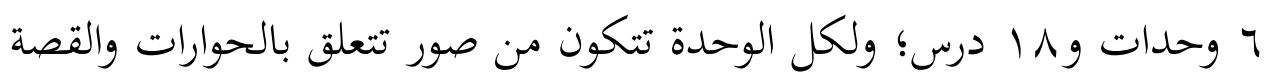

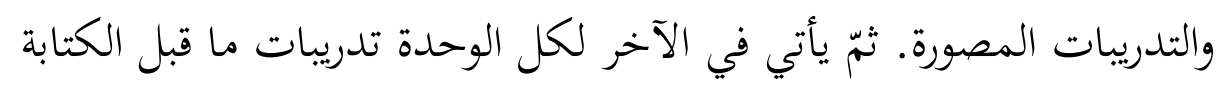
r) القسم الثاني إلى القسم الخامس تبدأ بهذه الوحدة مرحلة جديدة يشاهد فيها التلاميذ الحروف المكتوبة لأول

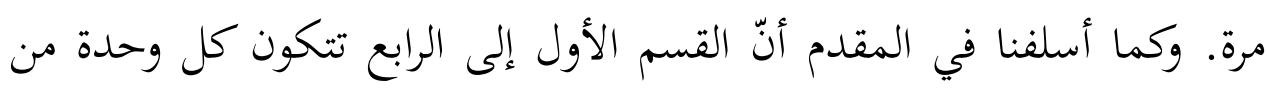
ثلاثة دروس وصفحة تدريبات الكتابة، أولها نص حواري والدرسان الآخران تدريبات عليه، إلا وحدة السادسة، فأولها نص قرائي لتثبيت ما درس في الحوارات الخسمة، ثم درسان للتدريبات والمراجعة.

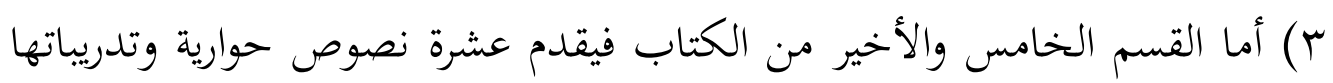
في الوحدات من الأولى حتى الخامسة، معدل حوارين في كل وحدة، وثلاثة نصوص قرائية وتدريباتها في الوحدة السادسة. 


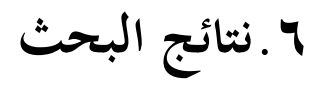

فبعد أن قام الباحث بتحليل البيانات، سيقدم الباحث هنا نتيجة من عملية

التقويم على كتاب العربية للناشئين. والكتاب يحتوي على العناصر الآتية:

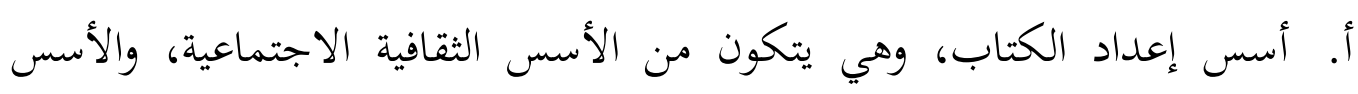

السيكولوجية، والأسس اللغوية والتربية.

1) أما الأسس الثقافية الاجتماعية؛ فالمراد منها هي الثقافة العربية والثقافة

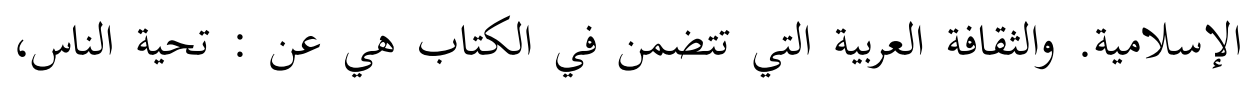

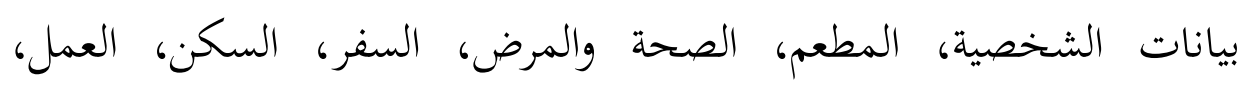

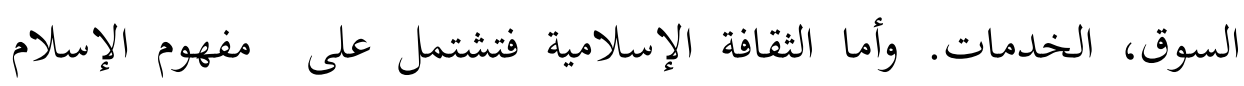

وأركانه فقط. وإضافة عن ذلك أنّ الكتاب يحتوي أيضا عن الثقافة العامة.

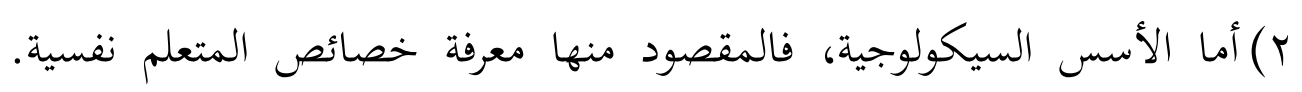

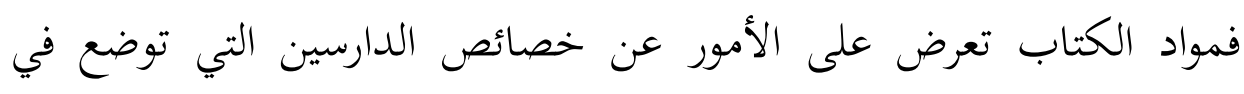

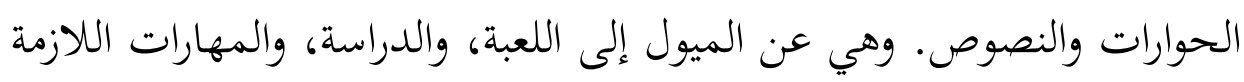

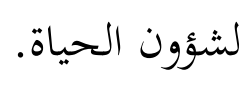

r) وأما الأسس اللغوية والتربية؛ فهي تتكون على ثلاثة عناصر: اللغة التي ينبغي

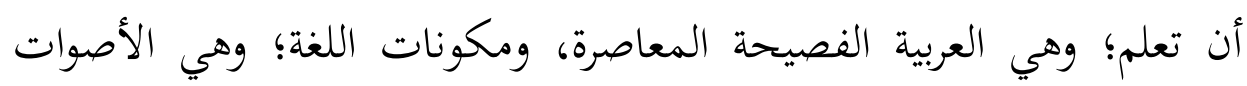
والمفردات والتراكب، ومهارة اللغة؛ وهي الاستماع والكالام والقراءة والكتابة. فكل هذه الأشياء تتضمن في هذا الكتاب.

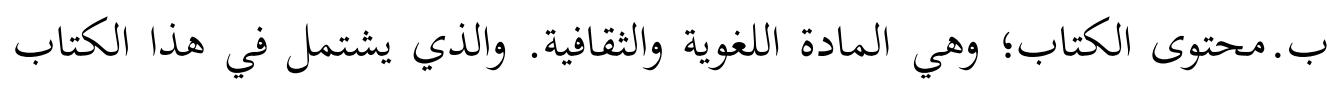

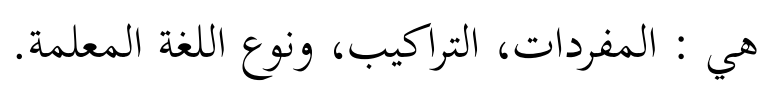

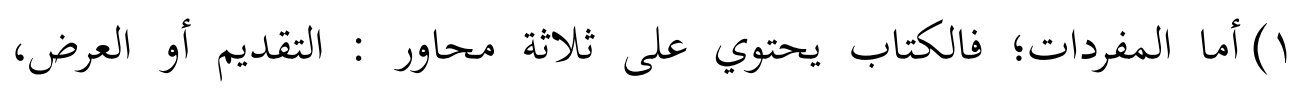

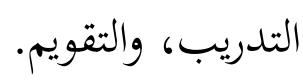


r) وأما التراكيب؛ فالكتاب يتكلم فقط عن تدرس التراكب النحوية الوظيفية.

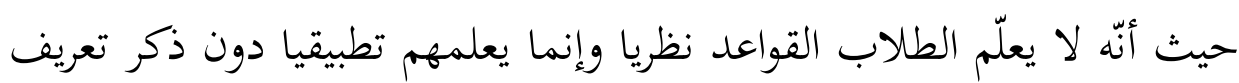
المصطلاحات النحوية.

r) وأما نوع اللغة؛ فالكتاب يستخدم اللغة العربية الفصيحة المعاصرة، وهي اللغة

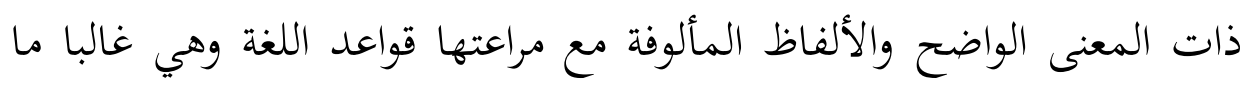

$$
\text { ج. المتب بها في الصحف والمجلات وغير ذلك من وساؤل الإعلام. }
$$

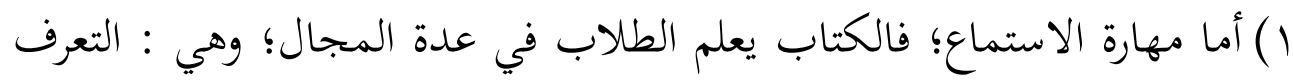

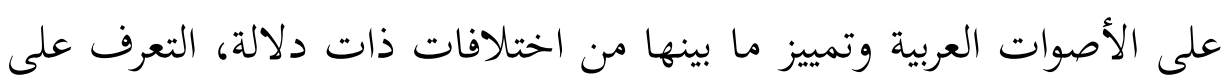
الحركات الطويلة والحركات القصيرة والتمييز بينها، التمييز بين الأصوات المتجاورة في النطق والمتشابهة في الصوت، إدراك العلاقات بين الرموز الصوتية والمكتوبة والتمييز بينها، التعرف على التشديد والتنوين وتمييزهما صوتيًا، فهم ما يلقي من حديث باللغة العربية وبإيقاع طبيعي في حدود المفردات المدروسة، ومتابعة الحديث وإدراك ما بين جوانبه من علاقات.

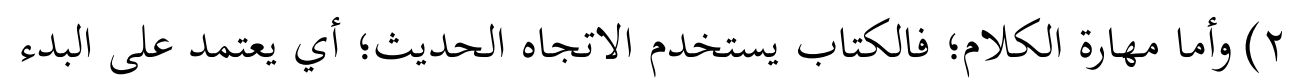
بالحوارات. ويطبق ثلاث مراحل فقط، هي : حوارات مغلقة الإجابة، حوارات مفتوحة الإجابة، والتعبير الموجه أو المقيد؛ التعبير عن أفكار قصيرة.

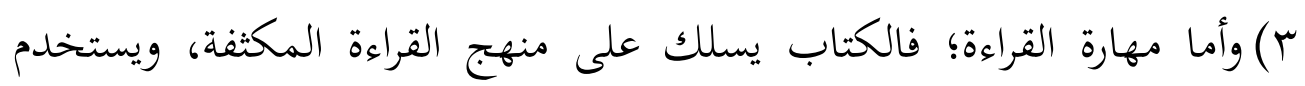

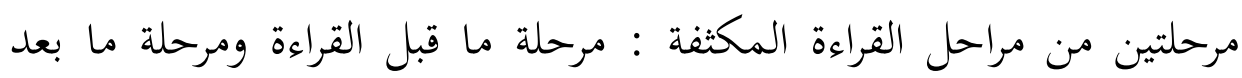
القراءة.

ع) وأما مهارة الكتابة؛ فالكتاب يستخدم ثلاث مراحل لتدريس مهارة الكتابة: المرحلة الأولى: التدريب على رسم الحروف؛ وهي أنواع : الكتابة من اليمين

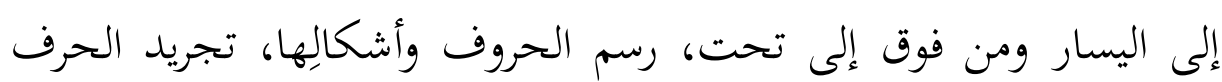

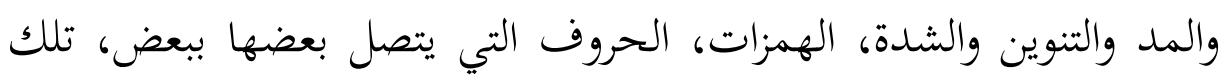


التي تتصل بحروف سابقة لها، ولا تتصل بحروف لاحقة، رسم همزات القطع

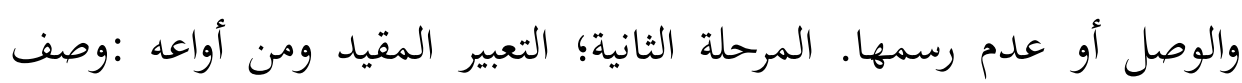

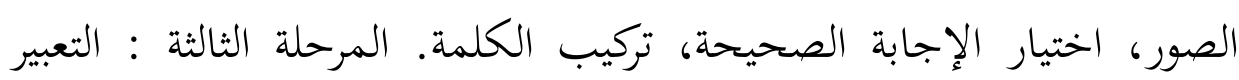

$$
\text { د. طريقة التدريس وهي الإنشاء. }
$$

يستخدم الكتاب الطريقة السمعية الشفوية في تعليم اللغة العربية. وهي لاهتمامه

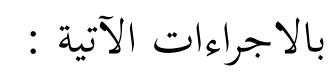

() أن يبدأ بتعليم الدارس مهارات الاستماع الجيد أولا ثم مهارات الكلام.

r) يأتي في الأهمية بعد مهارتي الاستماع والكلام مهارتا القراءة والكتابة ويفضل عند تدريس القراءة البدء بقراءة ما استمع إليه الدارس ونطقه، والتدرج مما له

$$
\text { ألفة به إلى ما لا ألفة به اعنه }
$$

r) يحظر استخدام لغة وسيطية في تعليم العربية كلغة ثانية سواء كانت هذه اللغة

$$
\text { الوسيطة هي اللغة الأولى للدارس أو غيرها من لغات. }
$$

ع) النحو جزء متكامل مع عناصر اللغة الأخرى. ومن ثم ينبغي تدريسه من خلال

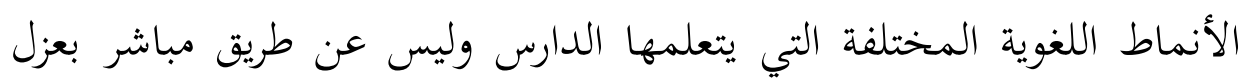

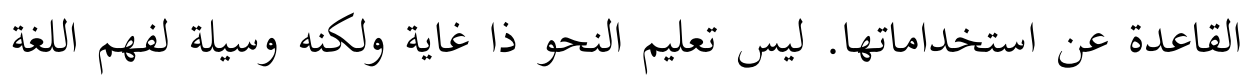

وتذوق أنماطها.

$$
\text { هـ التدريبات }
$$

فالكتاب يحتوي على ثلاثة أنواع التدريبات؛ هي: التدريبات الآلية/ تدريبات

$$
\text { و. المواد المصاحبة، الأنماط، تديبات المعنى، التدريبات الاتصالية. }
$$

أما المواد المصاحة للكتاب؛ فيشتمل على : كتب التدريبات والتمرينات،

$$
\text { ز. إخراج الكتاب. ومرشد المعلم أو كتاب المعلم. }
$$


فلإخراج الكتاب، فبيانه بالجدول التالي :

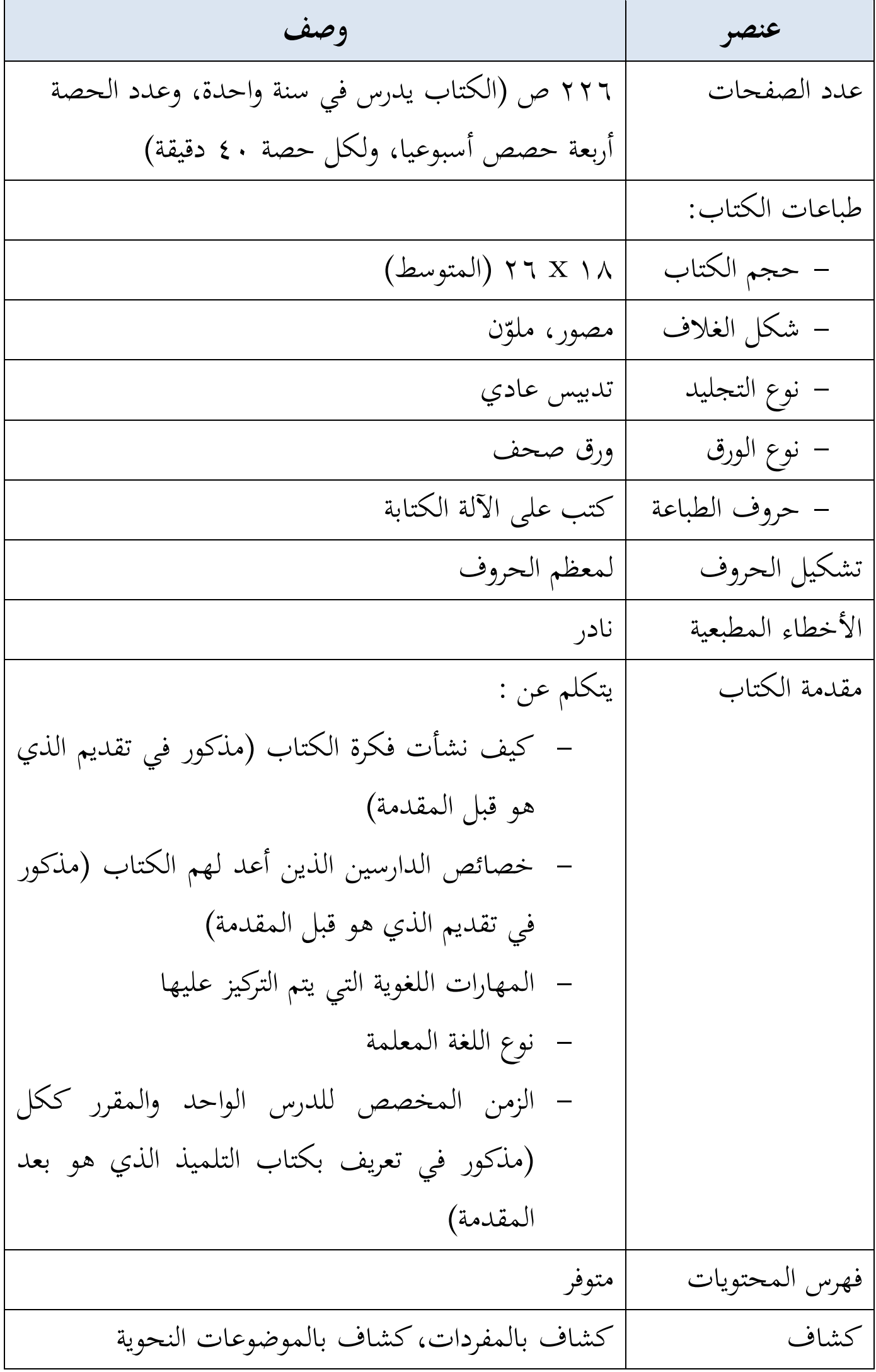




\begin{tabular}{|c|c|}
\hline مذكور في فهرس الأقسام والدروس & العناوين الداخلية \\
\hline 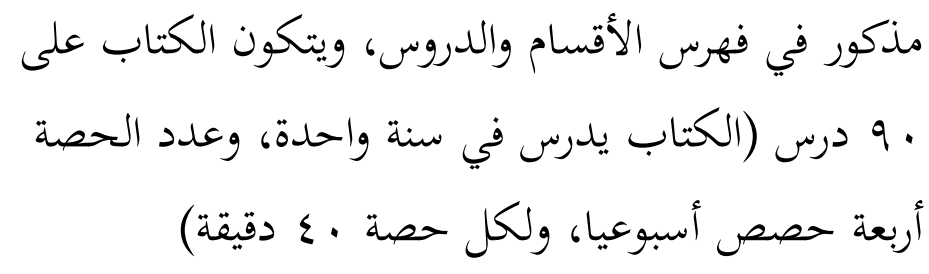 & عدد الدروس \\
\hline متوفر & الصور والرسوم \\
\hline
\end{tabular}

فنظرا من النتائج السابقة؛ رأى الباحث أنّ كتاب العربية للناشئين مطابق لتعليم

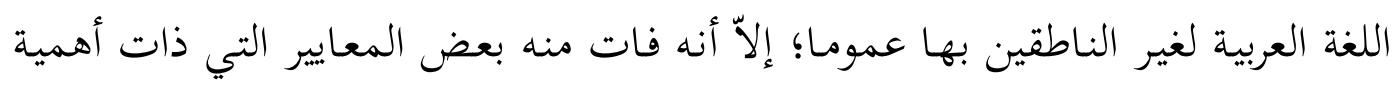

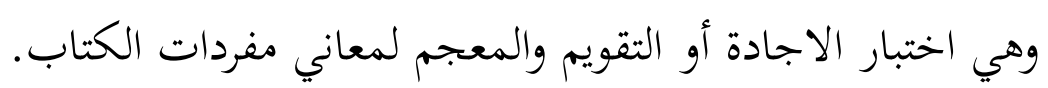

وكما يؤسف على الكتاب من عدم توفر وسيلة لتعليم مهارة الاستماع كأمثال

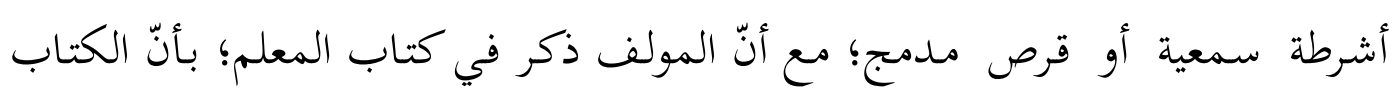

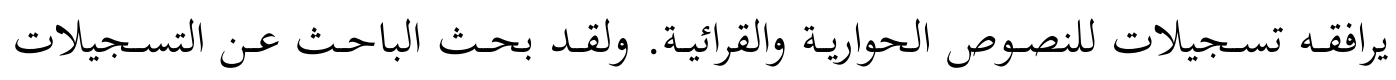

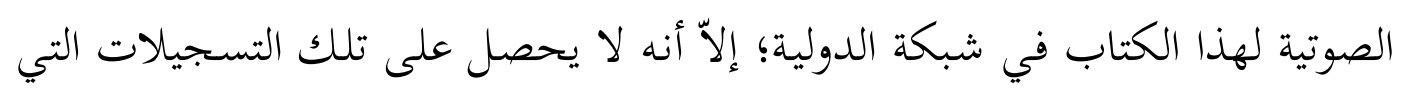
أصدرها المؤلف نفسه.

ومن ملاحظات الباحث أيضا على هذا الكتاب هي عن نوع الورقة؛ فالكتاب الذي يوبع في الدكاكن بعضه بورقة الصحف وغير ملوّن، وذلك يؤدي إلى عدم الفهم

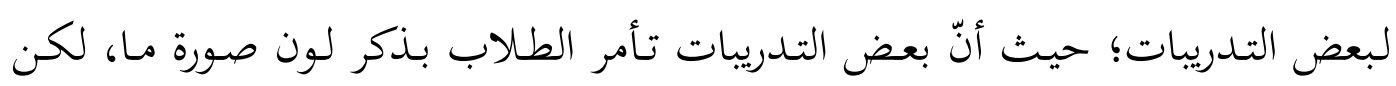
المطبوع من الكتابة والصور غير ملون إلا فقط لون الأسود أو الرمادي.

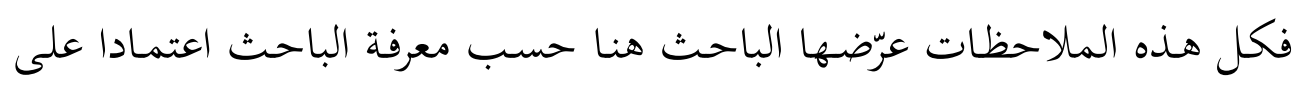
كتاب العربية للناشئين المنتشر ويوبع في الدكاكن والمحلات الموجودة في مدينة باكن بارو .

\section{الخاتمة والخحلاصة}

فالخلاصة من نتائج تقويم كتاب العربية للناشئين هي؛ أولا: ما يتعلق بمحتويات كتاب التعليمي "العربية للناشئين" وهي أسس إعداد الكتاب؛ يتكون من الأسس فئس 
الثقافية الاجتماعية، والأسس السيكولوجية، والأسس اللغوية والتربية، ومحتوى الكتاب؛ يشتمل على المادة اللغوية وهي : المفردات، التراكيب، ونوع اللغة المعلمة

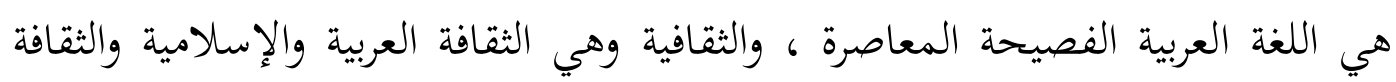
العامة، المهارات اللغوية؛ وهي الاستماع والكلام والقراءة والكتابة، وطريقة التدريس؛ فيستخدم الكتاب الطريقة السمعية الشفوية في تعليم اللغة العربية، والثدريبات؛

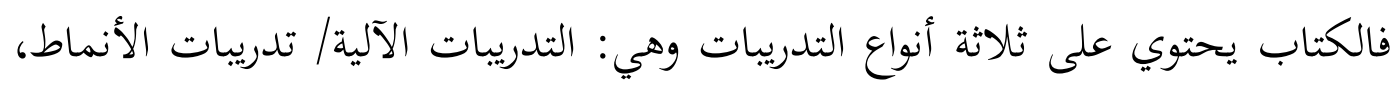
تدريبات المعنى، التدريبات الاتصالية، والمواد المصاحبة، يتكون من كتب التبدي التدريبات

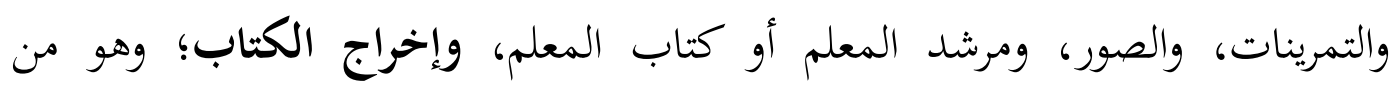

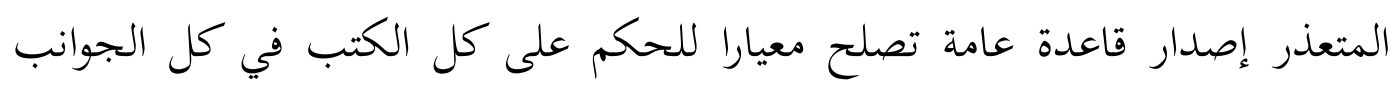
الخاصة بالطباعة.

ثانيا: أنّ كتاب العربية للناشئين مطابق لتعليم اللغة العربية لغير الناطقين بها

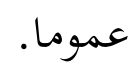

\section{المراجع والمصادر}

حمود إسمعيل صيني وأصدقاء. العربية للنشئين. لبنان: مؤسسة سعيد الصباغ. دون السنة.

حسن شحاتة وزينب النجار . معجم المصطلحات التربوية زالنفسية. القاهرة:

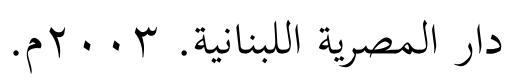

$$
\begin{aligned}
& \text { رشدي أحمد طعيمة. دليل عمل في إعداد المواد الثعليمية لبرامج تعليم }
\end{aligned}
$$

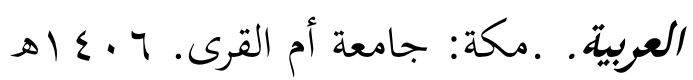

عبد الرحمن بن إبراهيم الفوزان. إعلداد مواد تعليم اللغة العربية لغير الناطقين 
محمد الدريج والأصدقاء. معجم مصطلحات المناهج وطرق التدريس. الرباط

$$
\text { مكتب تنسيق التعريب في الوطن العربي. }
$$

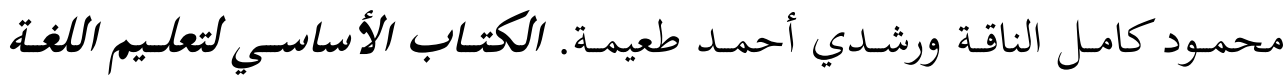

العربية للناطقين بلغات أخحي. مكة: جامعة أم القري. ب. مـ ا هـ.

ناصر عبد الله الغالي وعبد المجيد عبد الله. أسس إعلداد الكتب التعليمية لغير

الناطقين بالعربية. دون مكان الطباعة. دار الاعتصام. دون السنة. 